\title{
Molecularly based generic and species concepts and the field mycologist
}

In an article in the MycoLens section of the December issue of IMA Fungus, Vellinga et al. (2015) propose six simple guidelines for introducing new generic names of fungi. Whilst from the perspective of the mycological taxonomic researcher, their's stands as a valuable and pragmatic commentary, which lays down legitimate concerns and guidelines, it addresses few if any of the more practical challenges that face the collector and determiner in the field.

Recently, a fellow UK field mycologist predicted to me that in 20 years every species of 'bolete' will have a different generic name, and that this would be untenable in terms of field determination. We are already witnessing what many would regard, in terms of practical determination and listing, as mind-blowing complications being introduced into what were once easyto-follow generic concepts such as those of Boletus, Hygrocybe, Clitocybe, and Collybia. As Vellinga $e t$ al. provide us with timely reminders, we have seen 'Boletus' alone ballooning into no less than 24 new genera since 2000, 17 of these in 2014/15 alone according to my trawl of Species Fungorum. At least 247 new species that would, at one time, have been labelled 'Boletus' have appeared since 2000. Significantly, from the perspective of the field mycologist, a fair proportion of these new species will be discernible only after examination of their genetic profiles. There can be no argument that the genus 'Boletus' was, and remains, paraphyletic, but ad infinitum genus delimitation on criteria that can't be seen, smelled, touched, or put to simple chemical test, does not help the field collector and determiner, who would prefer, given the obvious practical realities of their craft, to be a 'lumper', not a 'splitter'.

As a field mycologist and manager of a major UK fungus records database, the present snowstorm of name changes, when attributable to phylogenetic research at molecular level, as opposed to other considerations, presents a serious dilemma. Do I slavishly keep expanding and revising generic and specific names on the database, and on what grounds? Where is the constructive benefit in revising Hygrocybe pratensis to Cuphophyllus pratensis other than to satisfy taxonomists who, I believe, often see the world from a rather closeted perspective, and do not have to deal with the practicalities faced by the field operatives who wear the responsibility of correctly pigeonholing their fungus collections.

The risk is a tangible one. Good field interest on which the evolving DNA-based science is dependent, not only to provide raw research material but also to develop consequent conservation strategies, is being discouraged and may ultimately be driven away.

Where will this leave conservation progress?

If no practical field inspection or test can determine a distinction between two species that are morphologically and anatomically identical, and which cannot be separated by accessible chemical tests, what is the point of placing them in different taxa? I suspect that we are a long way from the introduction of a handy field gadget into which tissue samples can be placed to analyse their genetic profiles and return accurate determinations. Put dried specimens with distinct DNA profiles in different boxes in the laboratory or museum by all means, and there is a provisional argument for the field operative sending specimens to be sequenced and dried down in such institiutions. However, this also carries a caveat, and it is a significant one. It seems doubtful, on present evidence, that many of the potentially recipient collections could cope with the deluge of perishable material that would follow. Pursuing such a course of action would also require that funding was made available for the extra costs involved to the field community.

I sense that at some point, sooner rather than later, there has to be a candid discussion about whether on the one hand taxons emerging purely as an outcome of phylogenetic analysis, and on the other the scientific names with which field mycologists have little choice but to label their collections on databases, should be maintained in separate boxes. I have worries about field recorders needing to add the suffix 'aggregate' to increasing numbers of records, but perhaps soon it will be their only option.

Sadly, we have a growing dichotomy between the aspirations of laboratory-based scientists engaging enthusiastically in DNA profiling, and the practical needs of the field recording and fungal conservation communities for whom much of what is currently evolving in the laboratory is, and is likely to remain, unintelligible and inapplicable.

Vellinga EC, Kuyper TW, Ammirati J, Desjardin DE, Halling RE, et al. (2015) Six simple guidelines for introducing new genera of fungi. IMA Fungus 6: (65)-(68).

Michael Jordan Chief Executive Officer, The Fungus Conservation Trust (mj@abfg.org) 